\title{
ELECTRON BACK-SCATTERED DIFFRACTION MISORIENTATION MAPPING APPLIED TO STRESS CORROSION CRACKING OF STAINLESS STEELS
}

\author{
M.A. Othon, L.N. Brewer, T.M., Angeliu, and L.M. Young \\ GE Global Research Center, Niskayuna, NY 12309
}

Stress corrosion cracking ( $\mathrm{SCC}$ ) is a persistent problem that limits metallic component life in a wide variety of environments. Because SCC is largely influenced by the crack tip oxide rupture rate, life prediction models require characterization of the crack tip strain rate for SCC cracks. Crack tip strain rate may be mathematically derived from crack tip strain; however, crack tip strain is difficult to characterize due to the required small scale of the measurement and its highly localized nature [1]. Measuring the spatial gradient in crack tip strain requires both sensitivity to plastic strain and high spatial resolution. EBSD and related techniques, such as electron channeling patterns, have been used with some success to measure plastic strain around cracks in Fe-3Si single crystals [2], $\mathrm{Cu}$ single crystals [3], and Ni-based superalloys [4], among others. In this paper, we will discuss the use of misorientation mapping as a means for visualizing plastic deformation around crack tips in air fatigue and stress corrosion cracks.

Two compact tension (CT) specimens were prepared from sensitized 304 stainless steel. One specimen was fatigue pre-cracked in room temperature air and then held at constant load (22 $\mathrm{MPam}^{1 / 2}$ ) for 20 hours at $288^{\circ} \mathrm{C}$ in argon . A second specimen was fatigue pre-cracked in room temperature air and then loaded to $30 \mathrm{MPam}^{1 / 2}$ in $288^{\circ} \mathrm{C}$ pure water with $2000 \mathrm{ppb}$ oxygen for a total of 2113 hours. Misorientation mapping was performed using standard EBSD mapping techniques with a commercial SEM (CamScan CS44) and commercial software (HKL Inc. Channel 5). EBSD scans of $400 \times 400,1 \square \mathrm{m}$ steps were made around the crack tips on polished $(0.05 \square \mathrm{m}$ silica $)$ samples from both the CT specimen surface and the mid-plane of each specimen.

EBSD maps of the air fatigued crack tip show a strong deformation zone extending several grains from the tip. A map of the high and low angle grain boundaries (Figure 1) displays a lateral spreading of deformation from the tip. The corresponding misorientation map (Figure 2) shows even further extension of the deformation zone around the crack tip. In both cases, the maps demonstrate a steep gradient in plastic deformation surrounding the crack tip.

EBSD maps of the SCC region display very little deformation around the crack and its tip. The grain boundary map (Figure 3) shows almost as many small angle boundaries in grains far away from the crack as near the crack, although a high density of low angle boundaries can be seen running along the crack plane itself. The misorientation map (Figure 4) also displays limited deformation confined primarily to the intercept between the SCC tip and triple junctions within the microstructure. Correlations between these observations and crack tip strains calculated from continuum mechanics models will be discussed.

[1] L.M. Young, P.L. Andresen and T.M. Angeliu, Corrosion/01, paper 131, NACE, Houston, TX , 2001.

[2] W.W. Gerberich, D.L. Davidson, and M. Kaczorowski, J. Mech. Phys. Solids Vol. 38, No. 1, pp. 87-113, 1990. 
[3] J. Ahmed, A.J. Wilkinson, S.G. Roberts, Journal of Microscopy Vol. 195, Pt 3, pp. 197-203, 1998.

[4] A.T. Tucker, A.J. Wilkinson, et al., Mat. Sci. and Tech., Vol. 16, pp. 427-430, 2000.

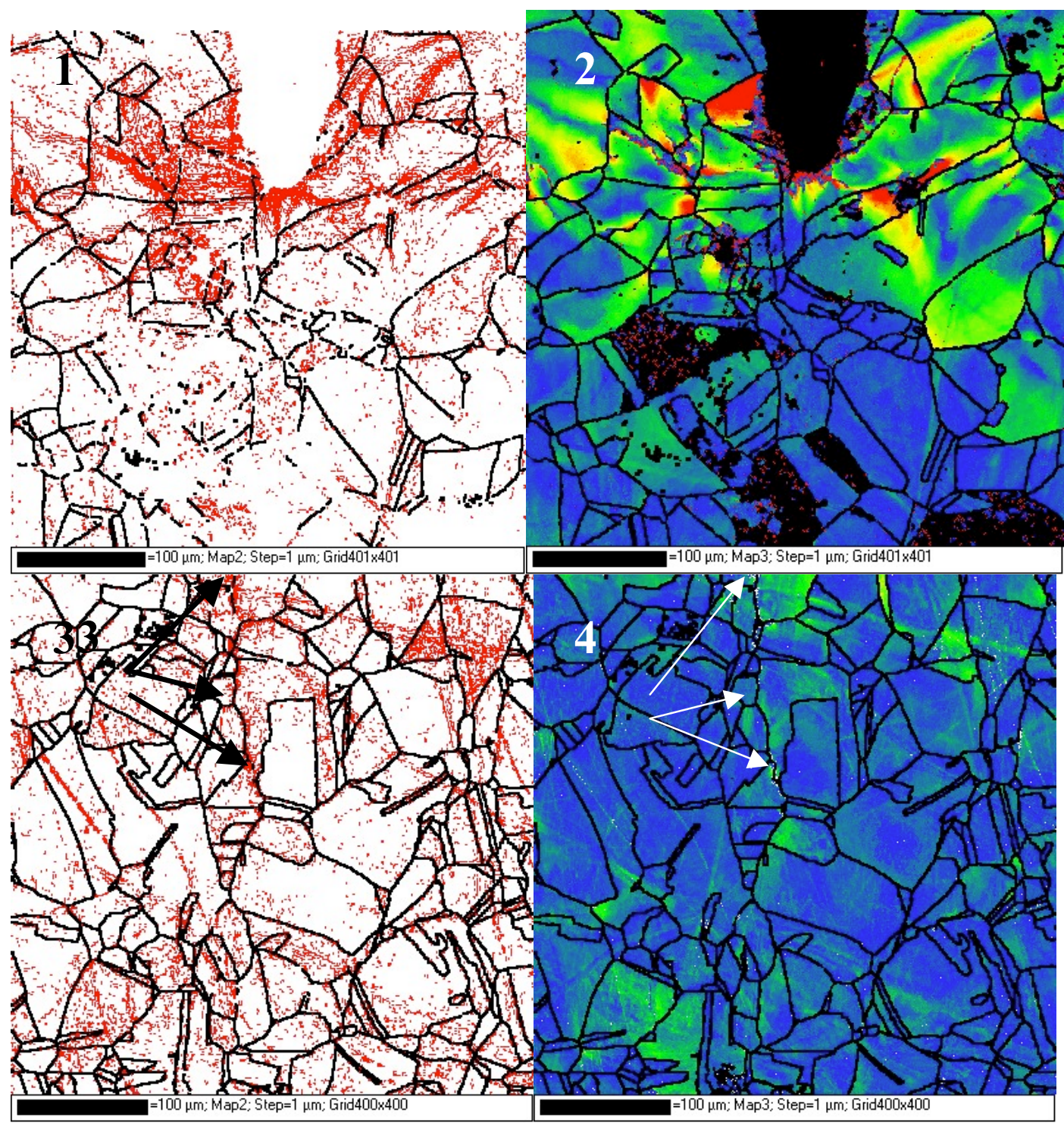

Figure 1. Grain boundary map of air fatigue crack. (black lines are high angle $\left(\square>10^{\circ}\right)$ boundaries, red lines are low angle $\left(2^{\circ}<\square<10^{\circ}\right)$ boundaries $)$.

Figure 2. Misorientation map of air fatigue crack (blue represents $0^{\circ}$ misorientation from internal reference, red represents $10^{\circ}$ misorientation from internal reference.)

Figure 3. Grain boundary map of stress corrosion crack. (black lines are high angle $\left(\square>10^{\circ}\right)$ boundaries, red lines are low angle $\left(2^{\circ}<\square<10^{\circ}\right)$ boundaries $)$. Arrows denote line trace of SCC.

Figure 4. Misorientation map of stress corrosion crack (blue represents $0^{\circ}$ misorientation from internal reference, red represents $10^{\circ}$ misorientation from internal reference.) Arrows denote SCC. 